\title{
ABORDAGENS DO BIOMA CERRADO, NO LIVRO DIDÁTICO: ESTUDO DE CASO NA ESCOLA ESTADUAL MARTINS BORGES NO MUNICÍPIO DE PIRES DO RIO - GO
}

\section{RESUMO}

\author{
Paulo Jean Pereira Alves' (paulo.jean@ifgoiano.edu.br), \\ Odelfa Rosa² (rosaodelfa@gmail.com) \\ 1 - Instituto Federal Goiano - Campus Urutaí \\ 2 - Universidade Federal de Goiás - Regional Catalão \\ https://doi.org/10.15628/geoconexoes.2019.7211
}

O estudo teve como objetivo discutir como tem se construído o contexto na relação dos alunos de uma escola da rede pública com as informações sobre os grandes biomas. No caso o Bioma Cerrado, e como o mesmo está sendo representado nos conteúdos do livro didático adotado. Entendendo ainda a relação que o professor promove para uma possível preservação e as ações que levam os alunos a formarem em relação às formas respeitosas sobre o meio ambiente. Para a realização da pesquisa foram utilizadas análises bibliográficas e pesquisa de campo. Foi possível assim observar as propostas que o livro e professor estão desenvolvendo entre os alunos, que os mesmos conhecem os problemas ambientais, e estão levando o conhecimento adquiridos ate os limites das paredes da sala de aula, com isso não apenas os alunos mas sociedade em geral são beneficiada.

Palavras-chave: Ensino, livro didático, cerrado.

\section{ABSTRACT}

This paper aimed to discuss how the context has been constructed in the relationship of the students of a public school with the information about the great biomes. In this case of the Biome Cerrado, and how it is being represented in the contents of the textbook adopted. Understanding also the relation that the teacher promotes for a possible preservation and the actions that lead the students to form in relation to the respectful forms on the environment. For the accomplishment of this research we used bibliographical analyzes and field research. Thus, it was possible to observe the proposals that the textbook and teacher are developing among the students, that they know the environmental problems, and are taking the acquired knowledge beyond the boundaries of the classroom walls, with this not only the students but also the society in general are benefited.

Key words: Teaching, textbook, Cerrado biome. 


\section{INTRODUÇÃO}

A Geografia é uma Ciência comprometida em tornar o mundo compreensível, explicável e passível de transformações, pois proporciona aos alunos a compreensão de sua própria posição no conjunto de interações entre a sociedade e a natureza. Na área das Ciências Naturais, no Ensino Fundamental, é incluído no estudo da Terra, sob responsabilidade principalmente dos professores de Ciências e Geografia, para as Ciências Naturais, os PCNs contribuem com assuntos relacionados a Ciência dentro da disciplina de Geografia no contexto interdisciplinar como estudo da Terra/Universo abordando seus respectivos conteúdos.

É consenso que o Cerrado é um importante domínio morfoclimático brasileiro, que abriga um número muito grande de espécies da fauna e flora do país. Seu solo é adaptável para receber diferentes culturas, seu clima é favorável ao desenvolvimento vegetacional, as principais bacias hidrográficas brasileiras estão localizadas neste domínio e dependem de seu equilíbrio para continuar existindo. Segundo Klink \& Machado, 2005. "sua biodiversidade pode contribuir para a produção laboratorial tanto de remédios como cosméticos, sendo uma possibilidade de visão para a sua conservação".

Contudo, a importância do bioma tem permanecido em discursos de preservação proferidos por grupos isolados em prol de uma intocabilidade e, assim, fazem com que continue propício à exploração desordenada pela sociedade, seja pela agricultura comercial, a urbanização ou até mesmo pelo processo de ocupação desordenado, dentre outros.

Uma das formas de contribuir com a conservação do bioma é através do ensino de conteúdos voltados aos recursos naturais. Conforme discutido por Seniciato (2002), "o pressuposto subjacente sobre essa vertente é de que, se os estudantes aprendem sobre a dinâmica dos ecossistemas, eles estarão mais aptos a decidir sobre os problemas ambientais e sociais de sua realidade", assim como para contribuir com a preservação do ambiente ao seu redor.

Possuindo cerca de $30 \%$ das espécies de plantas e animais do mundo, o Brasil, conta com uma variada fauna e flora, que estão distribuídas pelos sistemas de biomas que se apresentam pelo território brasileiro, levando a muitas pesquisas e conhecimento, no entanto muitas também sofrem com a falta de preservação.

O desconhecimento dos grandes Biomas do Brasil, a desvalorização de nosso patrimônio representado pela biodiversidade, aumenta as ameaças de extinção sobreestas espécies, especialmente, as do Bioma Cerrado que pouco se conhece.

Em virtude de suas características ecológicas, geopolíticas, demográficas, socioeconômicas e culturais, o Cerrado é considerado o bioma de integração nacional, ocupando uma área que cobre uma extensão estimada em 1,3 milhões de quilômetros quadrados do território brasileiro, distribuídos entre a totalidade do Distrito Federal, mais da metade dos Estados de Goiás (97\%), Tocantins (91\%), Maranhão (65\%), Mato Grosso do Sul (61\%), Minas Gerais (57\%), além de porções de outros 6 Estados (Pinto, 1990; Brandão, 1996; IBGE, 2004).

A grande biodiversidade cerradeira, sofre ameaças frequentes e tende a entrar num caminho de devastação e ate extinção, devido principalmente pela fronteira agrícola que chegou às regiões deste 
bioma na década de 1970 e aumentaram ao longo desses anos, levando a uma devastação da flora e dos demais recursos naturais do Cerrado.

A microrregião de Pires do Rio, foco deste trabalho, está inserida no bioma Cerrado e é uma das microrregiões do estado brasileiro de Goiás pertencente à mesorregião Sul Goiano. Sua população é estimada em 94.452 habitantes (IBGE, 2012) e está dividida em dez municípios, abrangendo uma área total de mais de $9.000 \mathrm{~km}^{2}$. Estudos têm demonstrado forte impacto antropogênico no bioma da região (Matos, 2012; Ribeiro \& Binsztok, 2008). Conforme discutido por Dias (2008), "o fato da agricultura moderna não ter se desenvolvido na referida microrregião em grande escala, não a livrou da degradação ambiental."

A degradação do bioma na região tem acentuado os problemas como: erosão dos solos, mudanças nos períodos de chuvas, assoreamento e desaparecimento de curso d'água, rebaixamento do lençol freático, os quais contribuem para a redução da sua biodiversidade, uma das mais ricas do Brasil e com uma grande quantidade de espécies endêmicas. Nesse sentido Dias, 2008, "compreendendo que o ensino sobre o Cerrado constitui estratégia particularmente importante para a conservação do bioma, com vistas não apenas à conservação do mesmo", mas também para a construção de conhecimentos sobre o bioma e conscientização da importância de que medidas preventivas contra a degradação devem ser adotadas, é importante que aspectos ligados ao ensino do Cerrado sejam investigados.

Dessa forma, o trabalho teve como objetivo geral interpretar o Cerrado goiano a partir da avaliação e percepção dos alunos do Ensino Fundamental II $^{\circ}$ fase, professores e gestores das escolas públicas do município de Pires do Rio - GO. Para se chegar ao objetivo geral do trabalho, teve como base os seguintes objetivos específicos: a) conhecer a percepção do bioma Cerrado dos "atores" das escolas públicas do município de Pires do Rio - GO. b) identificar os conhecimentos (estudantes, professores, gestores) sobre assuntos relacionados ao Cerrado, a fim de detectar aspectos bem sucedidos ou falhas na formação dos estudantes; c) identificar experiências didáticas positivas em prol da conservação do Cerrado e experiências administrativas que contribuem com o desenvolvimento do tema nas escolas; d) avaliar o conteúdo dos livros didáticos utilizados nessas escolas sobre o bioma Cerrado, com o intuito de inferir se esses recursos estão contribuindo com o trabalho dos docentes.

Nesse sentido, o estudo teve como justificativa há necessidade de conhecer a percepção do bioma Cerrado, através dos livros didáticos, da rede pública de ensino do município de Pires do Rio - GO, e avaliar como o Cerrado e sua conservação têm sido trabalhados nas escolas, observando as experiências positivas em prol da conservação, entre outros.

\section{A REPRESENTAÇÃO DO BIOMA CERRADO}

O Brasil é um país com dimensões continentais, com clima tropical favorável à biodiversidade animal e vegetal, além disso, a sua repercussão internacional se dá devido aos vastos biomas existentes em seu território, como: a Amazônia, a Floresta Atlântica, o Cerrado e outros. "Em virtude da diversidade e da vastidão das riquezas naturais dos biomas brasileiros, a sociedade as encara como inesgotáveis e infinitas", MARTINEZ (2006). 
O Cerrado é a segunda maior formação vegetal brasileira. O significado etimológico do termo tenta traduzir a característica geral do bioma, qual seja uma vegetação densa, de arbustos, e com árvores baixas e tortuosas que ali ocorrem sobre vários tipos de solos, sendo a maior parte destes bem drenados, profundos, ácidos, pobres em nutrientes e com alta saturação de alumínio. (GONÇALVES, 2015).

Para muitos o Cerrado, é reconhecido pela riqueza deáguas e biodiversidade. Entretanto, essa imensa diversidade em seu território sofreu graves transformações, advindas do processo de modernização do campo implementado por políticas governamentais e pacotes tecnológicos, acarretando grandes consequências no cenário socioeconômico e nas paisagens.

Sendo um termo de múltiplos sentidos o cerrado além de nomear o bioma, também designa seus tipos de vegetação, as formas de vegetação que o compõe, bem como pode qualificar cerrados, campos, os cerrados stricto sensu, os cerradões, as matas secas, as matas úmidas (de galeria e ciliares), veredas (buritizais) e formações brejosas, ALVES (2012). Esta pluralidade de sentidos pode dificultar uma conceituação única, mas reflete a imensa diversidade da região.

A pressão sobre o Cerrado tem aumentado exacerbadamente nas últimas décadas, fazendo com que seja, hoje em dia, o bioma brasileiro mais ameaçado de destruição. De acordo com BIZERRI e FARIA, 2003, "o Cerrado vem sendo devastado num ritmo bastante acelerado e a quase ausente ação governamental em impedir o processo de degradação parece refletir o reduzido interesse de boa parte da população brasileira em relação à conservação deste bioma.".

A destruição da diversidade biológica e cultural do Cerrado é avassaladora e ações visando modificações deste quadro não podem esperar uma reformulação geral da educação no Brasil. 0 Cerrado é pouco conhecido e valorizado por parte significativa dos professores e pelas escolas de um modo geral, e isto deve se refletir na valorização do bioma pelos alunos BIZERRI e FARIA, 2003, diz que \uma avaliação de preferências de estudantes entre imagens de animais e paisagens mostrou que a maioria tende a preferir imagens de elementos não relacionados ao Cerrado (como paisagens urbanas e animais domésticos) do que elementos típicos do Cerrado".

No passado, a falta de conhecimento e as incertezas sobre os principais fatores que causavam o desmatamento no Cerrado prejudicaram sua conservação e manejo. Isto leva a crer que é necessário investir-se inicialmente, e em caráter de urgência, na sensibilização e divulgação da conservação do Cerrado, levando assim que ele deixe de um segundo plano de importância, dentre as metas da escola.

\section{METODOLOGIA}

Trabalhando com a realidade do aluno, é possível fazer com que ele se interesse pela temática ambiental e é fundamental fornecer a eles diferentes experiências, numa visão ampla, não somente de seu espaço, mas de diferentes realidades. De acordo com Santos (2007, p. 09): "a escola educa; por sua vez também é responsável pela sociedade." A educação ambiental é uma forma abarcante de educação, 
através de um processo pedagógico participativo que procura infiltrar no aluno uma consciência crítica sobre os problemas do ambiente.

De acordo com BIZERRI e FARIA (2003), "a escola pode e deve ser atuante no sentido de transmitir hábitos e valores favoráveis à conservação do Cerrado". No entanto, o que se observa é o tímido envolvimento da escola com as questões ambientais de um modo geral. Neste sentido, deve-se destacar o papel fundamental que as instituições de pesquisa, especialmente as universidades, no caso do Brasil, devem assumir no processo de introdução da educação ambiental na sociedade e, no caso particular deste estudo, no $7^{\circ}$ ano do ensino fundamental segunda fase. Dentre as várias formas de ação, destaca-se a democratização do conhecimento sobre os temas ambientais, e em especial sobre o Cerrado.

Dentro do tema pesquisado, foram aprofundados diversos assuntos com os grandes biomas do Brasil, o bioma Cerrado, a conservação do bioma Cerrado, as tecnologias no Cerrado, problemas ambientais e as leis que reforçam a introdução da Educação Ambiental na grade curricular, pelo Ministério de Educação e Cultura, por meio dos Parâmetros Curriculares Nacionais-PCN's e da Política Nacional de Educação Ambiental - PNEA.

O livro didático analisado foi Expedições Geográficas dos autores Melhem Adas, Sérgio Adas, que leva ao educando e educador em uma viaje pelo mundo do conhecimento, transmitindo em sala de aula, questões de múltiplos interesses, por traz de sua produção. O livro traz em suas páginas um belo estudo sobre as regiões brasileiras, e ao ser estudado a região centro-oeste, o Cerrado é muito bem contextualizado, com foco na biodiversidade, destruição, a importância para a vida.

\section{RESULTADOS E DISCUSSÃO}

O estudo foi realizado com aluno do $7^{\circ}$ ano do ensino fundamental segunda fase do Colégio Estadual Martins Borges na cidade de Pires do Rio - GO sendo um total de 27 alunos. Para o desenvolvimento da pesquisa, realizou-se revisão nos livros didáticos da disciplina de Geografia, a fim de conhecer como estão sendo ministrados os conteúdos dos Grandes Biomas em especial do bioma Cerrado, e no que diz respeito à conservação desse importante bioma.

De início, a Secretaria de Educação Estadual, foi informada sobre o projeto. Em seguida, a escola e professores também foram informados a respeito do projeto, o universo da pesquisa compreendeu 27 questionários objetivando conhecer qual sua percepção sobre os principais problemas ambientais em torno do bioma Cerrado, e como o livro traz na visão do aluno a mensagem do bioma Cerrado. Destacase o uso do questionário na pesquisa científica como um rico suporte, que permite uma aproximação dos dados relativos ao objeto de estudo, permitindo atingir um grande número de participantes ao mesmo tempo, além de deixá-los mais à vontade para responder algumas questões mais delicadas do que na entrevista, além de o tempo de resposta ser menor (GIL, 2008).

A maioria dos alunos que respondeu a pesquisa tem entre 12 e 13 anos de idade, sendo que, nesta fase, os alunos estão em constante processo de formação de seus conhecimentos, com possibilidades 
de adquirirem maiores noções de Educação Ambiental, pois têm condições de colocá-las em prática e melhorar o meio em que vivem. 0 questionário foi elaborado com questões abertas, possibilitando ao aluno sua expressão sobre o Cerrado, quais sejam: 01 - 0 que é o Cerrado para você?, 02 - Você considera importante conservar o Cerrado?, 03 - Qual a contribuição do livro didático em sua formação? E 04 - Qual seu papel na propagação da preservação do Cerrado?

Em resposta a pergunta $01,36 \%$ dos alunos têm o Cerrado como natureza, em cujas respostas estão pautadas somente como elementos da natureza, com descrição de uma natureza intacta e perfeita, $44 \%$ apresentam uma resposta com um Cerrado humanizado, destacando um sujeito social, a cultura e 20\% responderam apenas que Cerrado é vida. Como podemos conferir no gráfico 01.

Figura 01 - Amostra o que é o Cerrado para você

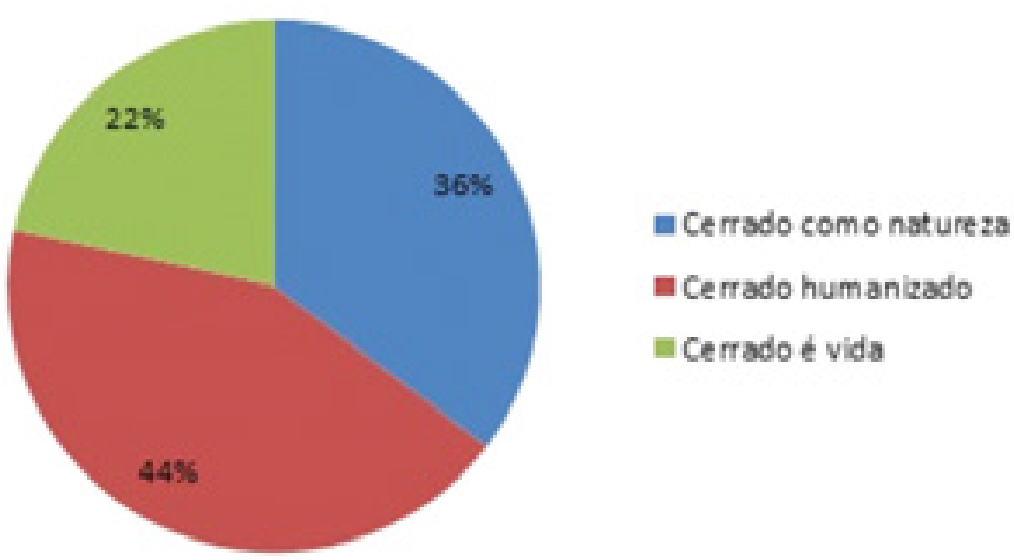

Fonte: ALVES, Paulo Jean Pereira.

Em resposta a pergunta 02, Você considera importante conservar o Cerrado? Todos responderam que sim, "pois Cerrado têm suas riquezas em plantas, animais e muitas pessoas que vivem". As respostas da pergunta $03,15 \%$ em evitar queimadas, $25 \%$ produzir menos lixo, $20 \%$ em preservar fauna e flora, $23 \%$ evitar poluição, e $17 \%$ evitar desmatamentos.

Figura 02 - Qual a contribuição do livro didático em sua formação.

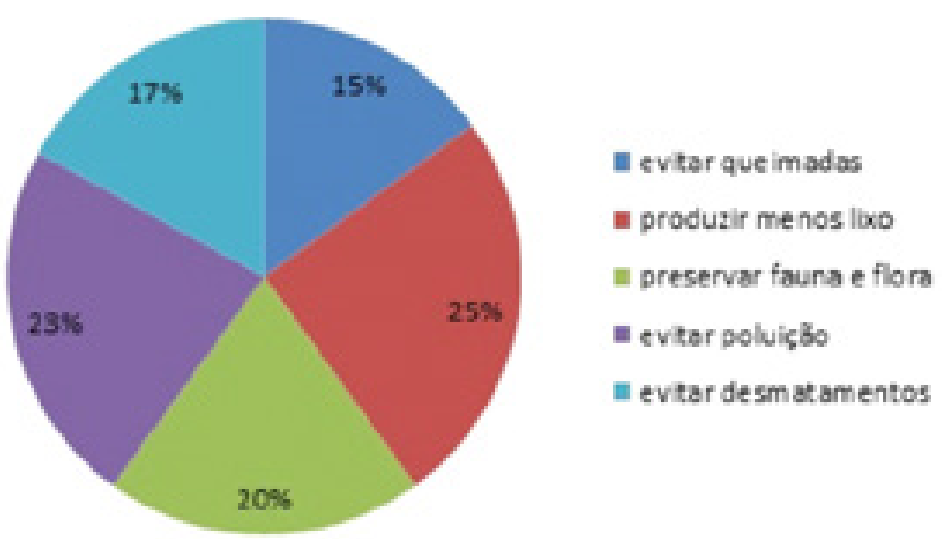

Fonte: ALVES, Paulo Jean Pereira. 
Ao ser perguntado ao aluno se ele já falou em preservação do Cerrado em casa, com seus amigos, ou em outro lugar, todos responderam que no seu dia-a-dia tem propagado os conhecimentos adquiridos em sala de aula e nos livros didáticos, e por isso, o trabalho com a Educação Ambiental e preservação do bioma Cerrado, não deve ser exclusiva da escola, mas de diversas outras instâncias sociais.

Nota-se a necessidade de que cada um tenha consciência e utilize os conhecimentos adquiridos sobre o bioma Cerado para ampliar suas ações benéficas, com isso clarear e mostrar caminhos, mas fáceis para que o aluno não sinta tanta dificuldade em assimilar um assunto em questão, ou seja, que ele desperte o interesse pelo estudo e, facilitando o papel no professor no ambiente escolar.

\section{CONSIDERAÇÕES FINAIS}

Através da pesquisa observou-se que os alunos têm tido contato com o conteúdo do livro didático, adquirindo conhecimentos importantes no seu dia-a-dia, que os levam a ter noções de como respeitar o meio em que vivem, de como por exemplo o valor de preservar uma a fauna e flora do Cerrado. Todos os alunos demonstraram que, pelo menos na teoria, sabem o que a preservação do bioma Cerrado é de suma importância para melhorar a relação do homem com o meio ambiente.

O livro didático é um caminho viável e seguro para o professor começar a formar as ideias e objetivos de sua aula, no entanto deve ser apenas um apontamento. As ações práticas que podem ser desenvolvidas em sala de aula são ilimitadas. Dessa forma, o professor de geografia ou mesmo ciências tem próximo do lugar possibilidades de apresentar ao aluno, praticas de proteção e conhecimento do Bioma Cerrado.

Diante de uma imensa biodiversidade, de uma qualidade de ecossistemas de vidas, o Bioma Cerrado ainda é pouco discutido no contexto da educação ambiental. No processo de orientação sobre as práticas de conservação das águas, da reciclagem correta, da proteção dos animais e outros seres, faltam ainda informações didáticas que possibilitam compreender o Cerrado enquanto um Bioma completo.

Espera-se assim que o contexto seja proveitoso para práticas e dinâmicas no processo de ensino-aprendizagem dos alunos. Partindo desse pressuposto cabe ao professor o papel de inovar e influenciar a utilização do livro didático em suas aulas para que se tenham resultados positivos e perceba a aprendizagem dos alunos.

\section{REFERÊNCIAS}

1. ALVES, Paulo Jean Pereira, MEIO AMBIENTE E EDUCAÇÃO: Necessidade de um Novo Modelo de Desenvolvimento, Trilhos: - Revista do sudeste Goiano/Faculdade do Sudeste Goiano. v. 1, n. 1 (2003) - Pires do Rio - GO: Gráfica Pires do Rio, 2011 - v. 7, (2011/2) v.: II. Color.

2. BRASIL. Secretaria de Educação Fundamental. Parâmetros curriculares nacionais: história, geografia/ Secretaria de Educação Fundamental. Brasília: MEC/SEF, 1998..

BIZERRIL, Marcelo Ximenes Aguiar, FARIA, Dóris S., A ESCOLA E A CONSERVAÇÃO DO CERRADO: UMA 3. ANÁLISE NO ENSINO FUNDAMENTAL DO DISTRITO FEDERAL; Departamento de Ecologia, Instituto de Ciências Biológicas, Universidade de Brasília; 2003. 